\section{Importance for the U.S. Pecan Industry of Communicating about Quality}

\author{
W.J. Florkowski, ${ }^{,}$, J.C. Purcell ${ }^{2}$, and E.E. Hubbard ${ }^{3}$ \\ Department of Agricultural Economics, The University of Georgia \\ Georgia Station, Griffin, GA 30223-1797
}

Additional index words. Carya illinoinensis, specialty crop quality, standards for grades

\begin{abstract}
Several standards for pecan [Carya illinoinensis (Wangenh.) K. Koch] grades and the relationship between selected quality attributes and prices indicated the complexity of communicating about quality attributes. Clear communication about quality attributes preferred by end users within the pecan industry and horticulturists facilitates the improvement of cultivars and strengthens the competitive position of the industry. A survey of Georgia pecan growers provided information about knowledge and perceived adequacy of pecan quality standards. Logit models were used to identify variables influencing knowledge of pecan grades and their perceived adequacy. Estimation results suggest that larger and more experienced growers were more familiar with the U.S. Dept. of Agriculture standards for grades than small and new growers. The geographical location of a grower did not significantly affect the results. Knowledge of quality attributes demanded by the market requires familiarity with standards for grades and with industry practices to develop improved pecan cultivars.
\end{abstract}

The objective of this paper is to address the complexity of communicating pecan quality attributes. Quality attributes are listed in quality standards and are reflected in the industry's pricing practices. The existing difficulties in uniform interpretation of quality within the industry preclude informing breeders and horticulturists about important quality attributes. Quality interpretation as-

Received for publication 12 Sept. 1991. Accepted for publication 4 Feb. 1992. The cost of publishing this paper was defrayed in part by the payment of page charges. Under postal regulations, this paper therefore must be hereby marked advertisement solely to indicate this fact.

Assistant Professor.

${ }^{2}$ Professor.

${ }^{3}$ Research Assistant. sists in the selection of tree characteristics that enhance the quality of pecan nuts. Higher quality is reflected in higher prices paid in the marketplace. An efficient market price should guide growers in planting decisions and would be a source of information to scientists who improve pecan cultivars.

To achieve its objective, the study includes a discussion of the relationship between selected quality attributes and prices paid for pecans. The study also includes a synthesis of growers' knowledge and perceived adequacy of pecan quality standards. The evaluation of growers' knowledge of quality standards is based on sample data. Familiarity with quality standards is tested using a qualitative dependent variable model.

Standards for grades and industry pricing practices are sources of information about quality attributes. Knowledge of standards for grades and observation of the industry's practices provide a more complete description to scientists working with the industry of quality attributes that are preferred by end users. Scientists working on improving pecan cultivars benefit from uniform interpretation of quality by easily identifying the industry's needs. Knowing these needs facilitates selection of genetic traits from available germplasm and transferring traits to improve cultivars.

Pecan quality standards. Standards for grades play an important economic role when buyers and sellers establish a transaction price for a specific commodity. Due to the existence of standards, buyers and sellers can conclude a transaction without physically inspecting a lot of in-shell or shelled pecans. Without well-defined and -communicated standards for grades, the price discovery process may omit essential information, making the market less efficient. Concerns expressed by pecan growers, accumulators, and shellers listed inability to communicate about pecan grades. Accumulators and shellers stated that growers were not knowledgeable about grades (Hubbard et al., 1988b). Thus, the pecan industry may fail to maximize market potential by supplying end users with pecans below consumers' quality requirements.

A need for delivering a consistent quality of pecans through improved grading was stressed several decades ago (Jones et al., 1932). Currently, an array of public and private grade standards for shelled pecans is employed voluntarily in market transactions. Public standards for grades were established by the U.S. Dept. of Agriculture (USDA; U.S. Dept. of Agriculture 1969, 1976). Standards for grades were also established by the Federated Pecan Growers' Assn. Private quality standards were developed by shelling companies and are used in marketing shelled pecans.

The presence of several sets of standards for pecan grades as well as changes in grade 
Table 1. Logit estimation results of knowledge and adequacy of pecan quality standards.

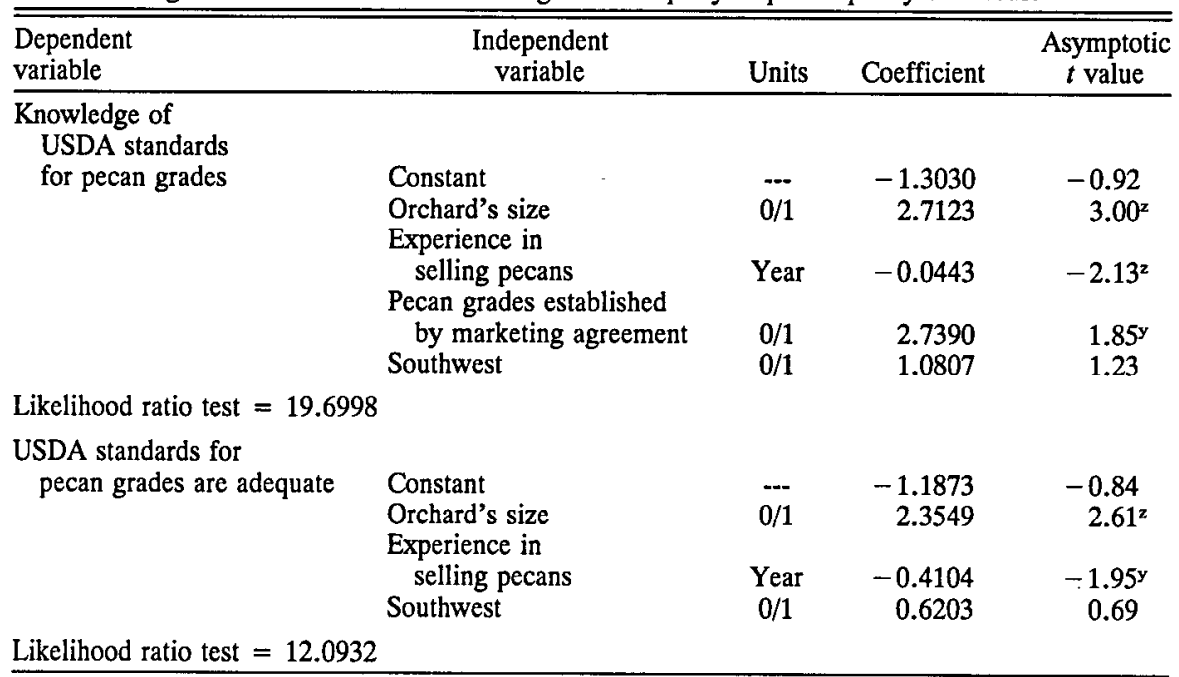

${ }^{2}$ Significant at $\alpha=0.05$.

ysignificant at $\alpha=0.1$.

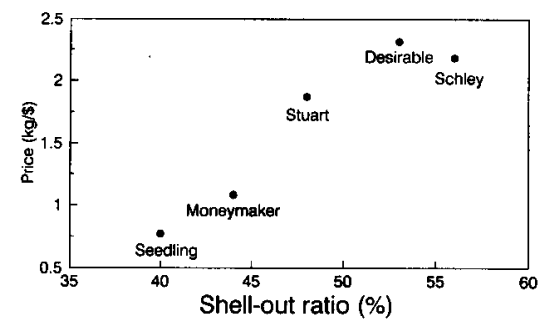

Fig. 1. Relationship between shell-out ratio and highest seasonal price for selected pecan cultivars in Georgia, large lots. 1987. Calculations based on the highest price paid for good quality large lots from Pecan Marketing Summary, 1987 crop, and the shell-out ratio and count from Goff et al. (1989).

specifications disrupt communication about pecan quality. Difficulties in communicating about quality are heightened by the change in the form of the product. Growers market in-shell pecans, while shellers market shelled pecans. Shellers' economic incentive is to recover as many pecan kernels as possible during shelling.

Pecan quality is reflected in prices shellers pay growers. Survey results of the pecan industry indicated that shell-out ratio, count (the number of nuts per kilogram), and kernel color were major criteria in evaluating pecan quality (Hubbard et al., 1990). The shell-out ratio for pecan cultivars varies from $42 \%$ to $63 \%$ (Goff et al., 1989). The shellout ratio is the ratio of the kernel weight to the in-shell nut weight. The shell-out ratio for the two major commercial cultivars in the Southeast is $48 \%$ for 'Stuart' and $53 \%$ for 'Desirable'; for 'Moneymaker' it is $44 \%$ and for 'Schley', $56 \%$. The shell-out ratio for southeastern seedlings is $\approx 40 \%$. Georgia price quotations distinguish among cultivars. Prices received by growers in Georgia tend to increase with the increase in the shell-out ratio (Fig. 1).

Price is also influenced by nut size. Count is a measure for the size of halves. Growers in the southeastern United States tend to re- veyed individuals. Seven percent of respondents did not answer.

Information from the survey offered an opportunity to identify variables influencing the knowledge of quality standards for pecans and their perceived adequacy by pecan growers. To identify important variables, two qualitative dependent variable models were specified. The selection of independent variables included in the models was determined by observation of the pecan industry and analysis of survey data.

The first relationship identified variables influencing the knowledge of the USDA standards for grades. These standards are widely used by the industry. Many standards for grades developed by the industry have been based on USDA standards. It was postulated that characteristics of growers influencing knowledge of quality standards are related to the size of the pecan enterprise. Growers operating $\geq 2000$ bearing-age trees were classified as large, and those operating $<2000$ were classified as small. Another important characteristic postulated to be related to the knowledge of USDA standards was experience in marketing pecans. In particular, growers who have marketed pecans for a longer period were postulated to have a better knowledge of standards than growers who had recently entered the industry. The last two digits of the year in which a grower began selling pecans represented the variable reflecting experience.

The second relationship was formulated to identify variables that influence the perceived adequacy of the public standard for quality. Orchard size, years of experience in marketing pecans, and geographical location of the pecan growers were the selected independent variables.

Both equations were specified as logit ceive a lower price for cultivars with smaller nuts (Fig. 2).

The survey data. Data were collected from 104 Georgia pecan growers who voluntarily participated in the survey during the 1987-88 harvesting season. For this survey, the state of Georgia was divided into three areas corresponding to the concentration of pecan production. Southwestern Georgia is the principal pecan-growing area. Among growers participating in the survey, nine growers were from northern Georgia, 27 from southeastern Georgia, and 68 from southwestern Georgia. The survey was conducted through personal and telephone interviews with growers.

The survey included questions probing growers' attitudes toward the development, implementation, knowledge, and adequacy of quality standards. Support for quality standards was expressed by $67 \%$ of growers in northern Georgia, $74 \%$ in southeastern Georgia, $91 \%$ in southwestern Georgia, and $85 \%$ statewide. The USDA was the choice of $38 \%$ of survey participants as an organization suitable to establish quality standards. Growers and shellers were the choice of $34 \%$ of respondents. Ten percent of survey participants felt that standards should be established only by growers. Various other suggestions were the choice of $11 \%$ of sur- models (Theil, 1976). In logit models, dependent variables are a function of an index of independent variables (Judge et al., 1982). The real dependent variable is unobservable (Maddala, 1983) and, therefore, it is defined as a binary variable assuming value 0 or 1 . In the case under consideration, the dependent variable assumed the value of 1 if the respondent knew about USDA standards for pecans, 0 otherwise. In the second equation, the dependent variable assumed the value of dards were adequate, 0 otherwise.

The number of trees operated was positively related to the knowledge of USDA standards (Table 1). Growers with large operations likely devote more time to marketing pecans than small operators for whom pecans provide a supplemental income. Experience in marketing pecan also positively influenced the knowledge of USDA standards. According to estimation results, growers with less experience in selling pecans had limited knowledge of USDA standards.

Growers who supported the idea of a marketing agreement establishing standards for grades had a better knowledge of the USDA standards. It is plausible that these growers preferred that an industry organization rather 1 if the respondent considered USDA stan- 
than a government agency decide the standards. The variable measuring the impact of the geographical location had no significant impact on the dependent variable. This result suggests that growers in the principal pecanproducing area did not have, on the average, a better knowledge of the USDA standards than growers in other regions.

Estimation results of the second equation, testing the perceived adequacy of USDA standards for pecan quality, were consistent with the results of the first model. In particular, large growers considered USDA standards adequate, but growers with little experience thought that USDA standards were inadequate. The variable accounting for geographical location of a grower had no significant impact on the dependent variable. This result suggested no differences among growers at various locations about the perceived adequacy of the standards.

Improved pecan quality should benefit the pecan industry. Large nuts, with a high shellout ratio, reduce handling and marketing costs. Our survey indicated that many Georgia growers acknowledged they were unfamiliar with past efforts to establish and regulate pecan quality standards. The knowledge of quality standards was particularly inadequate among operators of small orchards and those with limited marketing experience.

A major obstacle in redefining pecan quality standards is associated with the relationship between the in-shell pecans purchased by shellers and accumulators and the shelled pecan sold by shellers. The separation of quality standards for in-shell and shelled pecan is the reason why current standards do not fully describe quality attributes that influence prices paid to growers. The shell-out ratio, a major quality criterion used by the industry, is not included in existing quality standards. Information about quality attributes reflected in prices assists in selection of a cultivar for planting. Pecan cultivars maintain economic yields for decades, and replacement of an inferior quality tree is costly, given the historical series of pecan prices.

The cost-price squeeze considered as a major barrier to conditioned growth of the pecan industry was attributed to the piecemeal effort of the pecan industry to expand markets (Wood et al., 1990). An expansion of other tree nut production in the United States reduced pecans' share of the market. An expansion of pecan production and the anticipated increased supply of pecans (Hubbard et al., 1988a) can potentially increase the revenue of the pecan industry. To benefit fully from marketing a larger volume of pecans, growers and processors must maintain a steady supply of pecan with desired quality attributes. Quality attributes desired by end users have to be communicated to breeders of pecan cultivars and growers. Information about demanded quality attributes provides economic guidelines in allocating research funds and ranking research priorities. The ability of the pecan industry to assure consistently high quality is a positive factor in maintaining its share of the tree nut market.

\section{Literature Cited}

Goff, W.D., J.R. McVay, and M.S. Gazaway (eds.). 1989. Pecan production in the South-
east-A guide for growers. Auburn Univ., Alabama Coop. Ext. Serv., Circ. ANR-459.

Hubbard, E.E., W.J. Florkowski, and J.C. Purcell. 1991. Pecan value determination and quality perceptions of the Georgia pecan industry, p. 248-253. In: B.W. Wood and J.A. Payne (eds.). Pecan husbandry: Challenges and opportunities. Proc. Natl. Pecan Wrkshp., U.S. Dept. Agr., Agr. Res. Serv.-96, Washington, D.C.

Hubbard, E.E., J.C. Purcell, and T.F. Crocker. 1988a. Commercial pecan tree inventory and prospectus, Georgia, 1987. Ga. Expt. Sta. Res. Rpt. 554.

Hubbard, E.E., J.C. Purcell, and S.L. Ott. 1988b. Georgia survey reveals marketing practices of accumulators, shellers. Pecan South including Pecan Quart. 22(5), 5-7, 15-18, 28.

Jones, S.A., V.C. Childs, R.S. Washburn, B.H. Thibodeaux. and H.E. Rutland. 1932. An economic study of the pecan industry. U.S. Dept. Agr. Tech. Bul. 324.

Judge, G.G., R.C. Hill, W.E. Griffiths, H. Leutkepohl, T. Lee. 1982. Introduction to the theory and practice of econometrics. Wiley, New York.

Maddala, G.S. 1983. Limited-dependent and qualitative variables in econometrics. Cambridge Univ. Press, London.

Theil, H. 1976. Principles of econometrics. Wiley, New York.

U.S. Dept. of Agriculture. 1969. United States standards for grades of shelled pecans. USDA, Washington, D.C.

U.S. Dept. of Agriculture. 1976. United States standard for grades of pecan in the shell. USDA, Washington, D.C.

Wood, B.W., J.A. Payne, L.J. Grauke. 1990. The rise of the U.S. pecan industry. HortScience 25:594, 721-723. 